\section{Tourismus im Aufwind!}

\section{Tagung zu internationalen Standards, zum Beratungsmarkt und zu Bonn als globaler Destination}

Am 23. und 24. September fand im Geographischen Institut der Universität Bonn eine Tagung zum Thema „Tourismus im Aufwind“ statt. Eingeladen hatten der Arbeitskreis Freizeit + Tourismus des Deutschen Verbandes für Angewandte Geographie e. V. (DVAG) sowie die Deutsche Gesellschaft für Internationale Zusammenarbeit (GIZ) GmbH (Sektorvorhaben „Tourismus und nachhaltige Entwicklung'c). Burghard Rauschelbach und Kai Partale führten als Moderatoren durch das Programm. Die Veranstaltung erfuhr großes Interesse bei Praktikern und Wissenschaftlern. In drei großen Blöcken setzten sie sich mit verschiedenen Aspekten des Themas auseinander.

Im ersten Themenblock ,Tourismus als Instrument für nachhaltige Entwicklung: überfordert, unterschätzt?“ berichtete Burghard Rauschelbach
(GIZ) über die entwicklungspolitische Bedeutung des Tourismus. Über die Rolle nichtstaatlicher Organisationen bei der Gestaltung des internationalen Tourismus reflektierte Heinz Fuchs von Tourismwatch (Evangelischer Entwicklungsdienst); Günter Koschwitz (TourCert, Gesellschaft für Zertifizierung im Tourismus) referierte $\mathrm{zu}$ den Möglichkeiten und Grenzen von Zertifizierungen im Tourismus.

Im zweiten Themenblock „Tourismus in Deutschland: Ein Exportgut?" informierten Randolph French und Sarah Lopau vom Deutschen Tourismusverband e. V. über die verschiedenen Qualitätsinitiativen des DTV. Isabelle Lindel (Tourismus \& Congress $\mathrm{GmbH}$ Region Bonn, Rhein-Sieg, Ahrweiler) zeigte am Beispiel des Konferenzstandortes Bonn, wie das Thema Nachhaltigkeit vor Ort umgesetzt und international vermarktet wird.

Im dritten Themenblock „Berufsbild Tourismus: Was braucht man als Touristiker?" zeigte Prof. Dr. Ralf Lanwehr (Internationale Hochschule Bad Honnef), wie Change Management im Rahmen der Entwicklungszusammenarbeit im Tourismus funktioniert. Kai Partale (Benchmark Services) gab einen Überblick über die verschiede- nen Beratungsmärkte im Tourismus sowie über Herausforderungen, die sich hieraus für die universitäre Ausbildung ergeben.

Flankierend zu den Vorträgen wurden ausgewählte tourismusbezogene Projekte sowie Forschungsergebnisse auf Präsentationswänden vorgestellt und diskutiert.

Am zweiten Tag trafen sich die Teilnehmer in der Bonn-Information und diskutierten mit Cordula Faust (Bonn Information) und Arnulf MarquardtKuron (Amt für Wirtschaftsförderung Bonn) über die Wirkung Bonns auf internationale Besucher. Ein stadtgeographischer Rundgang unter dem Leitthema „Tourismus als prägendes Element Bonns" rundete die Veranstaltung ab.

Kai Partale

\begin{abstract}
Abb. 1 Tagungsteilnehmerinnen und -teilnehmer beschäftigen sich vor Ort mit der Rolle des Tourismus in Bonn. In der Mitte (mit Kamera) Exkursionsleiter Arnulf Marquardt-Kuron, ganz rechts Burghard Rauschelbach (GTZ), Mitveranstalter und Co-Moderator der Veranstaltung (Foto: Partale)
\end{abstract}

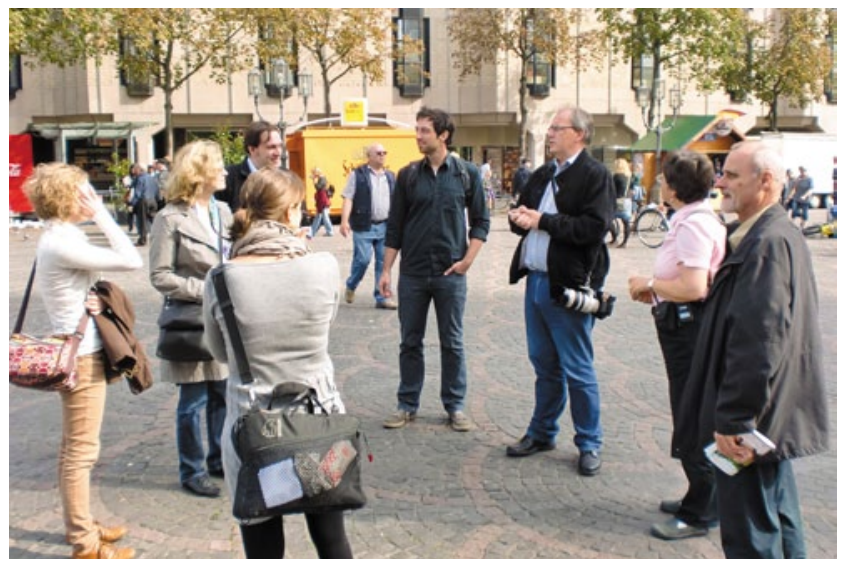

Online publiziert: 8. November 2011

算 Springer 